\title{
Review of The methodology of positive economics: reflections on the Milton Friedman legacy, ed. Uskali Mäki. Cambridge: Cambridge University Press, 2009, 382 pp.
}

\author{
JULIAN REISS \\ EIPE, Erasmus University Rotterdam
}

Friedman's 1953 essay "The methodology of positive economics" is undoubtedly one of the-or perhaps the-most influential and most widely and hotly debated papers on economic methodology. What economic methodologist would not dream of having more than 2,500 citations in Google Scholar for writing "the only essay on methodology that a large number, perhaps majority, of economists have ever read" (Hausman 1992, 162)?

At the same time the essay appears somewhat difficult to interpret and, to the extent that it has been interpreted, controversial. Indeed, many different methodological perspectives have been read into it. According to one interpreter, the essay "provides ingredients for a number of doctrines, such as fictionalism, instrumentalism, positivism, falsificationism, pragmatism, conventionalism, social constructivism, and realism" (Mäki 2003, 504) and "What the reader is served is an F-mix, a mixture of ingredients many of which are ambiguous and some of which are hard to reconcile with one another" (Mäki, 90 [all undated page references are to the volume under review]); according to another, "One can find in it echoes, and sometimes much more than echoes, of Popper, Kuhn, Quine, Toulmin, Laudan, and even Feyerabend" (Blaug, 351). But this apparent confusion does not stop commentators taking a firm view on its worth: methodologists and philosophers have generally taken a very critical stance, whereas the majority of practising economists seems to endorse its conclusions, whatever they are taken to be (Hands 2001, 57).

It should be no surprise, then, that more than half a century after its publication, the essay still attracts an audience. The book under review is the outcome of a 2003 conference held at Erasmus University Rotterdam to celebrate the 50th anniversary of the essay's publication. According to its editor, the volume collects papers that "were 
commissioned from what was close to the best possible team of scholars on the theme" (p. xviii).

It would be interesting to find out what this alleged 'theme' is supposed to be. The only thing that is clear after reading the book is that Friedman's 1953 methodological stance is not it. This is as startling for a book that has the same title as Friedman's essay as it is disappointing for those-like me-who are interested in economic methodology and hope to learn something new about methodological issues. Rather, the book comprises papers on a wide variety of topics that are more or less loosely related to Friedman's essay, such as its genealogy, its historical context, whether it caused the formalist revolution, whether it licensed the formalist revolution, what type of methodology Friedman as a practising economist endorsed, and many more.

The absence of new material on the 1953 essay was particular disappointing to me as a methodologist because: (a) I do not think the essay is quite as obscure as some commentators make it appear"Actually, it is at once wonderfully ambiguous and incoherent" (Blaug, 351) - ; (b) in my view, the position Friedman does defend in the essay has not made itself sufficiently heard in recent times; and (c) the only chapter in the book that explicitly deals with Friedman's 1953 stance (Mäki, 90-116) makes an utterly implausible case that the essay can be read (or 're-read', or 're-written'; see the title of Mäki's paper) as a statement of realism. Let me go through these points in turn.

Ignoring labels for the time being, there can be no doubt about some of Friedman's 1953 methodological ideas. They can easily be summarised in two prescriptions. The first prescription is that the aim of 'positive' economics-along with the philosophical climate of his time and most economists up to this day, Friedman believed in a strict dichotomy between a realm of economic 'facts' and another one of 'values'-is to devise theories or hypotheses that successfully predict economic phenomena within some domain of relevance (i.e., economists ought to conjecture such theories or hypotheses). The second prescription is that economic theories or hypotheses ought to be evaluated on the basis of the significance of their assumptions and not their descriptive accuracy.

The qualifier 'within some domain of relevance' of the first principle is necessary to make the two principles coherent because an assumption implies itself. If, for instance, some theory assumes that businessmen 
maximise expected revenues (Friedman, 21) whereas in fact they price at average cost (p. 22), the theory can be taken to predict that businessmen maximise expected returns, which, being incorrect, would invalidate the theory. But once a domain of relevance is identified (for Friedman in this case market prices and quantities), assumptions and predictions can be distinguished.

The second principle has a positive and a negative part. To start with the latter, Friedman thinks that the fact that an economic theory contains false assumptions does not by itself speak against the theory. It is a methodological truism that false theories can be predictively accurate-Tycho's geocentric system saved the phenomena no less than Copernicus's heliocentric system for instance (McMullin 2009). To argue that a theory is inadequate because it contains false assumptions means therefore to commit a methodological fallacy. However, that does not mean that the assumptions are irrelevant for evaluating a theory or that theories are to be evaluated only with respect to their predictive success. Rather, and this is the positive part of the second principle, assumptions should be 'significant', by which Friedman means they should "explain much by little"-i.e., be simple and fruitful at the same time (Friedman, 10). When he criticises the theory of monopolistic competition for instance (p. 34ff.), Friedman never talks about its predictive success. He rejects it because there is an alternative theory (neoclassical economic theory) that is based on simpler and more fruitful assumptions. Thus, providing both theories are equally 'valid' (p. 8f.)-equally predictively successful-the neoclassical theory is preferable.

This is not the place for a full-fledged defence of Friedman's methodology. But since, as mentioned above, nearly all philosophical commentators have been highly critical, let me suggest at least one reason why his position might not be quite as unattractive as many philosophers and methodologists have made it look.

The slogan "Essentially, all models are wrong, but some are useful" (Box and Draper 1987, 424) has often been quoted, in economics and in many other sciences. Many sciences are heavily model-driven, and economics is no exception. Models are false by their very nature. Rather than sets of statements, models are representations of their targets. All representations must, on pain of utter uselessness, simplify, abstract, approximate, idealise, and what have you. 
Those who think that truth is the aim of economics, or that understanding economic phenomena is its aim and only true accounts provide genuine understanding, have difficulty coming to terms with this fact. For not all the ways in which a typical model distorts reality are equally harmless. In rare cases, one can ignore an idealisation because although it is literally speaking false, it is still approximately true because the idealisation makes a negligible difference. But many models, especially in economics, are better described in the following terms:

A model may give a totally wrong-headed picture of nature. Not only are the interactions wrong, but also a significant number of the entities and/or their properties do not exist (Wimsatt 2007, 102, emphasis in the original).

I will say a little more below about the kinds of examples Friedman discusses. What should be clear is that to the extent that such models play an indispensable role in economics, as almost everyone agrees they do, those who think that economics should aim for more than Friedmanstyle usefulness have a lot of explaining to do.

Back to Friedman. As long as it is understood that the above two principles form the core of Friedman's methodology, it does not matter a great deal what label one attaches to it. Almost every label that has been proposed captures some aspect correctly but is at the same time somewhat confusing because of the connotations it brings with it. 'Instrumentalism' correctly captures the idea that lack of descriptive accuracy in a theory's assumptions is not a reason to reject it, but at the same time suggests that 'anything goes' as long as the theory predicts successfully, which is not Friedman's position. 'Positivism' correctly captures Friedman's emphasis on prediction at the expense of explanation (he puts the latter term in scare quotes whenever he uses it), but suggests an epistemic concern with unobservables that Friedman does not have. 'Pragmatism' correctly captures Friedman's aiming at practical usefulness rather than truth and the central role user interest or purpose plays in his methodology, but it suggests a denial of the factvalue dichotomy, in which Friedman was a firm believer. 'Fictionalism' correctly captures the idea that for a theory to be useful it does not have to be literally true, but it ties Friedman's methodology to a little known and relatively obscure work of philosophy (Vaihinger 1924; but see Fine 1993). 
All the just mentioned philosophies are quite closely related, however, and have one thing in common: they are anti-realist. Realism is their common enemy. In this light, it is all the more astonishing that the only chapter in the book that is fully devoted to Friedman's 1953 methodology tries to present it as a statement of realism (Mäki, 90-116). How can its author, an accomplished methodologist, make such a mistake?

Key to the misinterpretation may be Friedman's continued use of a physics example to illustrate methodological points. The law that predicts that the distance travelled by a falling body is $s=1 / 2 g t^{2}$ (Friedman, 16) is, when applied to a compact ball dropped from the roof of a building, literally speaking false, because it assumes that the body falls in a vacuum. But since air resistance makes a negligible difference for this application, the hypothesis is useful nonetheless. Moreover, even when air resistance makes a non-negligible difference, for instance, when the falling body is a feather rather than a ball (p. 17), the hypothesis is useful because it predicts the contribution gravity makes to the fall. Gravity, like other forces in mechanics, continues to contribute to outcomes even when its operation is impeded by other causal factors such as air resistance.

But the mechanical example is exceptional and therefore misleading as an illustration of Friedman's methodological points. The test case for his principles is the economic hypothesis that firms behave as if they were rationally seeking to maximise their expected returns (p. 21)-after all, he wrote the paper in response to the marginalist controversy (Backhouse, 235ff.). But 'maximising expected returns' is not analogous to 'being subject to $f=m a$ ' for at least three reasons. First, the maximising hypothesis does not have the right form to be a hypothesis about a causal factor that continues to contribute to an outcome in the presence of impeding causal factors. A businessman whose pricing decisions are partly determined (say) by a fairness norm does not maximise returns, not even approximately. One either maximises or one does not, maximising a little is like being a little bit pregnant.

It is easy enough to come up with related hypotheses that have the right form. It is not incoherent, for instance, to say that businessmen seek both wealth and fairness. Economists then might focus on what happens when the wealth motive operates unchecked by other motives. The problem with this suggestion is that, by and large, what economic factors do depends on the whole setting in which they are embedded. 
To talk about what gravity were to do if it operated all on its own makes sense because situations can be created in which gravity does operate all on its own-or very nearly so. By contrast, to ascribe a wealth motive to businessmen is nonsensical unless certain kinds of institutional structure are presupposed. Indeed, applying the term 'businessman' presupposes such an institutional setting. In turn, details of the structure in which any motive of action is embedded will influence the behaviour that is caused by the motive. Thus, unlike physical forces, which have a stable contribution to outcomes independently of context, what economic factors do tends to be more context-specific. Therefore, what we learn about how certain motives-such as seeking wealthoperate when other motives for action are absent, even if correct for that situation, tends not to be very useful for predicting what happens in more complex situations.

Third, Friedman thinks that actual businessmen use an average cost pricing rule (p. 22). Suppose he is right. This would mean that the assumption that they maximise revenue is not idealising away other causal factors, but rather portraying a radically different factor, an 'entity or property that does not exist' in Wimsatt's words, as being responsible for outcomes of interest.

On all three counts, therefore, to assume that businessmen maximise returns is to give a totally wrong-headed picture of society. No realist defence of idealisation I can think of can make sense of this part of Friedman's story. And this is the essential part of his story.

Putting aside the fact that there is very little about the methodology of Friedman 1953 in this book, and that what there is is highly implausible to say the least, the remaining essays do contain some interesting and useful material. Dan Hammond recounts the genesis of the essay and how it changed from drafts into the published version in response to comments from other economists such as George Stigler. Thomas Mayer tries to answer the question of whether the essay caused the changing appearance of economics in the second half of the twentieth century (the 'formalist revolution'). Wade Hands asks whether it licensed the formalist revolution and in particular who is right between Blaug and Hutchison, who have argued that it did, or Mayer, who has argued that it did not. (Hands's short answer is that Mayer is right.) Melvin Reder assesses to what extent empirical evidence can bear on the neoclassical theory of wage setting. David Teira and Jesús Zamora argue that Friedman proposed his principle that the validity of 
economic hypotheses is determined by their predictive success as a way to gain the trust of public opinion regarding the claims established by the profession. Roger Backhouse locates the essay in the context of the marginalist controversy of the 1940s. Oliver Williamson writes about the theory of the firm and that it badly needs (but as of lately, also makes) testable empirical predictions. Jack Vromen provides a critical survey of selection arguments in favour of the maximising hypothesis. Chris Starmer contrasts the explicit methodology of the 1953 essay with two 'methodology in action' pieces written by Friedman with Leonard Savage in 1948 and 1952. Kevin Hoover inspects the implicit methodology of Friedman as a practising economist and identifies it as 'causal realist'. Michel De Vroey asks whether there really is a divide between 'Marshallian' and 'Walrasian' economics, as Friedman claimed in a paper written in 1949 (though not in the 1953 paper). Mark Blaug looks at the debate over the essay after 50 years and argues that "Friedman may have won some methodological battles", but "lost the methodological war" (p. 353) because, as he demonstrated in his Monetary history of the United States (Friedman and Schwartz 1963) Friedman sought 'thick evidence', that is, a wide variety of different kinds of mutually corroborating evidence, whereas most of the profession contends with narrow or 'thin' econometric evidence. A 'Final word' by Friedman himself concludes the book.

If one understands the book as one on Friedman rather than the 1953 essay, it is quite a pleasure to read.

\section{REFERENCES}

Box, George E. P., and Norman R. Draper. 1987. Empirical model-building and response surfaces. New York (NY): John Wiley \& Sons.

Fine, Arthur. 1993. Fictionalism. Midwest Studies in Philosophy, 18 (1): 1-18.

Friedman, Milton. 1953. The methodology of positive economics. In Essays in positive economics, Milton Friedman. Chicago: University of Chicago Press, 3-43. Reprinted in The methodology of positive economics (2009), ed. Uskali Mäki. Cambridge: Cambridge University Press, 3-42.

Friedman, Milton, and Anna Schwartz. 1963. A monetary history of the United States, 1867-1960. Princeton: Princeton University Press.

Hands, D. Wade. 2001. Reflection without rules: economic methodology and contemporary science theory. Cambridge: Cambridge University Press.

Hausman, Daniel. 1992. The inexact and separate science of economics. Cambridge: Cambridge University Press.

Mäki, Uskali. 2003. 'The methodology of positive economics' (1953) does not give us the methodology of positive economics. Journal of Economic Methodology, 10 (4): 495-505. 
McMullin, Ernan. 2009. Hypothesis in early modern science. In The significance of the hypothetical in the natural sciences, eds. Michael Heidelberger, and Gregor Schiemann. Berlin: Walter de Gruyter, 7-38.

Vaihinger, Hans. 1924. The philosophy of 'as if': a system of the theoretical, practical and religious fictions of mankind. London: Routledge and Keagan Paul.

Wimsatt, William. 2007. Re-engineering philosophy for limited beings: piecewise approximations to reality. Cambridge (MA): Harvard University Press.

Julian Reiss is associate professor in the faculty of philosophy at Erasmus University Rotterdam. His research focuses on the philosophy of science, the history and philosophy of economics, and philosophy of medicine. His latest book is Error in economics: towards a more evidence-based methodology (Routledge, 2008).

Contact e-mail: <reiss@fwb.eur.nl>

Website: <www.jreiss.org> 